\title{
Publisher Correction: Recent global decline in endorheic basin water storages
}

Jida Wang (D), Chunqiao Song, John T. Reager —D, Fangfang Yao, James S. Famiglietti, Yongwei Sheng, Glen M. MacDonald, Fanny Brun (1D, Hannes Müller Schmied (1), Richard A. Marston and Yoshihide Wada (1)

Correction to: Nature Geoscience https://doi.org/10.1038/s41561-018-0265-7, published online 30 November 2018.

In the version of this Article originally published, in the section 'Defining endorheic regions' in Methods, the sentence starting "These watersheds were aggregated..." contained the phrase "( 100,000 thousand $\left.\mathrm{km}^{2}\right)$ "; this should have read $\left(\sim 100,000 \mathrm{~km}^{2}\right)$ and has now been amended. 